\title{
Effect of In-Office Bleaching on Color and Surface Roughness of Composite Restoratives
}

\author{
Randa Hafez ${ }^{\mathrm{a}}$ \\ Doa Ahmed ${ }^{b}$ \\ Mai Yousryc \\ Wafa El-Badrawy ${ }^{d}$ \\ Omar El-Mowafye
}

\section{ABSTRACT}

Objectives: The purpose of this study was to determine color changes and surface roughness of composites when they were subjected to in-office bleaching.

Methods: 12 discs $15 \mathrm{~mm}$ in diameter and $2 \mathrm{~mm}$ thick were prepared from two shades (A2 \& A4) of two composites, Durafil VS (DF) and TPH3 (TPH). Specimens were polished and stored in distilled water for 24 hours at $37^{\circ} \mathrm{C}$ before being subjected to bleaching, staining, and re-bleaching. Each of the groups of specimens (DF-A2, DF-A4, TPH-A2 and TPH-A4) were subdivided into three subgroups $(n=4)$ and bleached with Beyond, LumaWhite-Plus, and Opalescence-Boost. Specimens were then stained by immersing them in a coffee solution for 48 hours at $37^{\circ} \mathrm{C}$, and then they were re-bleached. Colorimetric measurements were performed at baseline, after bleaching, after staining, and after rebleaching. Surface roughness was determined with environmental SEM before and after bleaching. Data were statistically-analyzed.

Results: None of the bleaching systems notably changed the color of composites (delta-E<2). Coffee staining affected DF specimens more than TPH. Stained specimens showed variable responses to whitening with no significant color change observed with TPH (delta-E<2) and significant changes observed with DF. Surface roughness significantly changed with bleaching, but the degree varied according to composite shade and bleaching agent.

Conclusions: Three in-office bleaching agents had no significant color changes on two composites. DF showed more color change than TPH when immersed in coffee. Stained composites showed different degrees of whitening, with DF showing more response. Bleaching may adversely affect the surface texture of composites. Dentists should take into consideration that composite restorations may not respond to bleaching in the same way that natural teeth do. (Eur J Dent 2010;4:118-127)

Key words: In-office bleaching; Surface roughness; Composites; Color change.

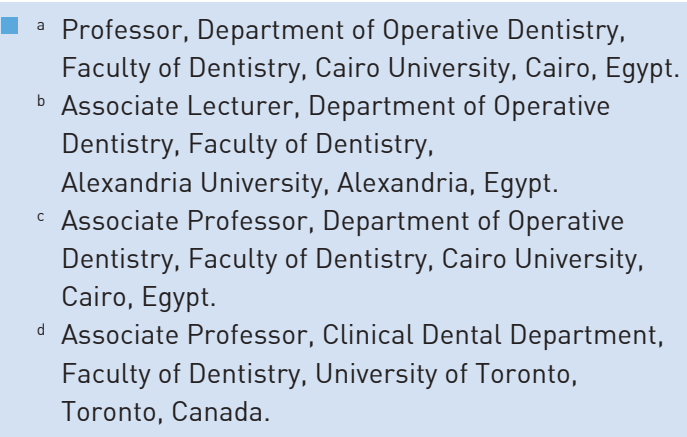

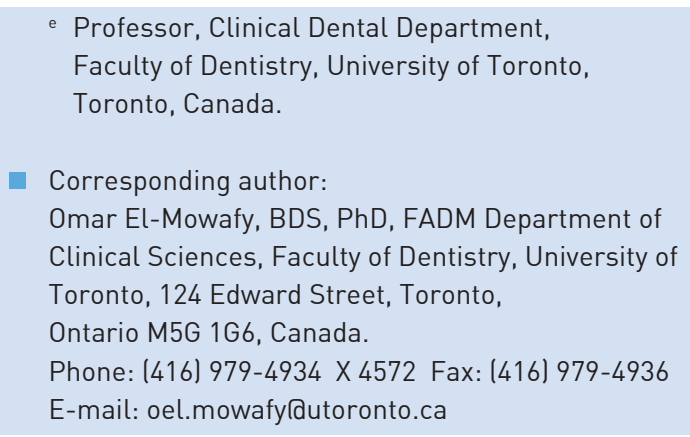




\section{INTRODUCTION}

The aesthetic appearance of anterior teeth has become a major concern for patients. Discolored vital anterior teeth have long been treated with different approaches, including crowns, direct and indirect veneers, composite resin restorations, and, most conservatively, bleaching. Both take-home and in-office bleaching techniques have proven effective in whitening teeth, with the latter having the advantage of producing immediate results. ${ }^{1,2}$

The typical in-office bleaching regimen involves application of a high-percentage hydrogen peroxide formulation to the teeth surfaces, which is activated either chemically or by a light source. The theoretical advantage of using lights is their ability to heat hydrogen peroxide, thereby enhancing the rate of oxygen decomposition. The increased amount of oxygen-free radicals produced thus enhances the release of stain-containing molecules and, therefore, results in enhanced whitening. ${ }^{3,4}$

The literature is rich with reports concerning the effects of in-office bleaching on natural teeth, but its effect on tooth-colored restorations is not, as yet, fully known. Resin composites are widely used as restorative materials because of their excellent aesthetic properties. However, their initial color may change over time as a result of surface and marginal staining, as well as internal material deterioration. ${ }^{5,6}$ Staining of resin composites by beverages such as coffee, tea, and soda or by mouth rinse agents has been reported to varying degrees. $^{7-9}$ In addition to color, surface characteristics contribute significantly to the aesthetic quality of restorations. Surface roughness has a detrimental effect on light reflection, resulting in a dull appearance that stands out from the rest of the teeth. Moreover, rough surfaces promote bacterial plaque adhesion, with subsequent increased staining. ${ }^{10-13}$

Anterior composite restorations are typically made with either microfilled or microhybrid formulations, depending on the class of the cavity. In the microfilled formulations, ultrafine inorganic filler particles with mean diameters of .04 microns are used. These render such materials highly polishable, but due to the limited amount of inorganic fillers that can be incorporated into such formulations, their mechanical properties are typically less than those of the microhybrid versions.
Therefore, their use is limited to non-stress-bearing restorations. In contrast, modern microhybrid composites have a variety of sizes of fine inorganic fillers with a mean value of less than 1 micron. Because of their high inorganic filler content, such materials are suited for the stress-bearing situations such as Class 4 restorations.

Monaghan et $\mathrm{al}^{14}$ reported that $30 \%$ hydrogen peroxide bleaching produced a significant color change in freshly prepared specimens of different composites. On the other hand, Hubbezoglu et al ${ }^{15}$ found that bleaching with $35 \%$ hydrogen peroxide resulted in composite resin color change values of a lesser magnitude. However, the ability of bleaching to remove acquired stains has not, as yet, been fully investigated. With regards to surface properties, some reports indicated that bleaching agents containing 30 to $35 \%$ hydrogen peroxide did not affect the surface texture as revealed by profilometric analysis. ${ }^{16,17}$ Nevertheless, analysis of surface reflectance showed significant changes in microfilled and hybrid composites. ${ }^{16}$

The purpose of this study was to determine color change and surface roughness of two composites, a microfilled and a microhybrid, when subjected to coffee staining and bleaching using different light- and chemically activated in-office bleaching systems. The null hypothesis was that the two composites will respond similarly to the different bleaching agents.

\section{MATERIALS AND METHODS}

Two commercially available resin composites, Durafil VS (Heraeus Kulzer, Wehrheim, Germany) and TPH3 (Dentsply Caulk, Milford, USA), were used in this study. Durafil VS (DF) is a microfilled composite composed of $40 \%$ volume silicon dioxide fillers and BisGMA matrix, while TPH3 is a microhybrid composite composed of $58 \%$ volume barium-alumino-boro-silicate, fluoro-boro-silicate fillers, and a matrix of BisGMA and TEGDMA. Twenty-four specimens, $15 \mathrm{~mm}$ in diameter and $2 \mathrm{~mm}$ thick, were fabricated from each material ( 12 of shade A2 and 12 of shade A4) using flexible molds. Each specimen was prepared as one increment and light-polymerized from each side for 40 seconds using a QTH light unit with intensity of $850 \mathrm{~mW} / \mathrm{cm}^{2}$ (Optilux 501, Kerr, USA). Specimens were polished with silicon carbide paper and each group of 12 specimens was subdivided into three 
subgroups ( $n=4)$, with each assigned to a bleaching agent. Specimens were stored in distilled water at $37^{\circ} \mathrm{C}$ for 24 hours and then subjected to bleaching using one of three in-office agents. Hydrogen peroxide concentration and $\mathrm{pH}$ of the bleaching gels as well as mode of application recommended by the manufacturers are listed in Table 1.

All subgroups were subjected to an initial bleaching session, after which color and surface roughness were measured. The specimens were then stained by placing them in a coffee solution prepared by boiling 3.6 grams of coffee powder (Nescafe Classic, Nestle, Switzerland) in $300 \mathrm{ml}$ of distilled water for 10 minutes, then filtering it. Immersion in the coffee solution was maintained for 48 hours at $37^{\circ} \mathrm{C}$, after which the color of specimens was determined before subjecting them to a second bleaching session. Color assessment was performed using a colorimeter (Chroma Meter CR 300, Minolta Co. Ltd., Japan), which was calibrated before every session following the manufacturer's instructions. The colorimeter displayed the different color parameters ( $L^{*}, a^{*}$ and $b^{*}$ ) according to the CIELab color system, where $L^{*}$ describes the luminance reflectance, while $a^{*}$ and $b^{*}$ describe the red-green and yellow-blue color coordinates, respectively.

The change in color from baseline was calculated after the first bleaching session $\left(\Delta E_{1}\right)$, after staining $\left(\Delta \mathrm{E}_{2}\right)$, and after the second bleaching session $\left(\Delta E_{3}\right)$. The change in color after the second bleaching compared to the color after staining $\left(\Delta \mathrm{E}_{3 \mathrm{~S}}\right)$ was also calculated. $\Delta \mathrm{E}$ values were obtained using the Hunter's equation: ${ }^{18}$

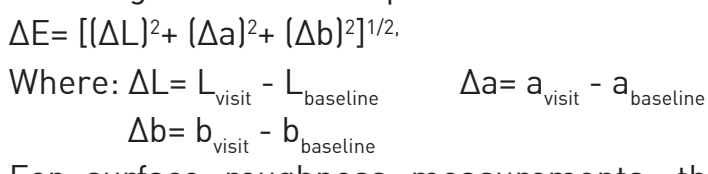

For surface roughness measurements, the specimens were examined for topographical quality using an Environmental Scanning Electron Microscope (ESEM) (Quanta 200, FEl Company, Philips, Netherland). Specimens were photomicrographed at 1000 times magnification and the images were analyzed quantitatively using image analysis software. A three-dimensional surface roughness profile was automatically plotted. At the Z-axis, the peaks or surface elevations were marked, and the height of each peak was automatically computed. Mean surface roughness values (Ra) were calculated for each specimen. Ra describes the arithmetic mean of all values of the roughness profile (R) over the evaluated length.

Data were statistically analyzed using SPSS 15.0 package (Chicago, Illinois). Regression models with two-way ANOVA and Tukey's post-hoc tests were used to test significance for the effects of composite material and bleaching agent on color and surface roughness at P $\leq .05$. Pearson's correlation coefficient was used to determine significant correlations between color and surface roughness measurements.

\section{RESULTS}

Mean color change $(\Delta E)$ results are shown in Tables 2 and 3 . The initial bleaching resulted in minimal color changes $\left(\Delta \mathrm{E}_{1}<2\right)$ in all subgroups regardless of the bleaching agent used. Tukey's Post Hoc test indicated no significant difference between DF and TPH3 in both composite shades (Tables 2 and 3). However, Beyond showed significantly higher bleaching results $(\mathrm{P}=0.009)$ in shade A2 only as compared to the other groups.

Staining of the specimens resulted in a more perceivable color change. In addition, mean $\Delta \mathrm{E}_{2}$ values were higher in the DF subgroups compared to the TPH3, with the difference significant only in shade $A 4$ ( $P=0.001$ ) (Table 2). In shade $A 2$, specimens previously bleached with LumaWhite-Plus showed significantly higher staining $(P=0.025)$ compared to the other two bleaching systems (Table 3). Values for $\Delta E$ for after staining are preceded with a negative sign to indicate that the color change was to a darker shade.

The color difference after the second bleaching session from baseline was higher in DF subgroups compared to TPH3; however, the difference was only statistically significant in shade A4 $(P=0.035)$ (Table 2). The type of bleaching system used showed no statistically significant effect on $\Delta \mathrm{E}_{3}$ in any of the composite subgroups (Table 3).

In regards to $\Delta \mathrm{E}_{3 \mathrm{~S}}$, which denotes the ability of the bleaching to remove acquired stains from the treated composite resins, the DF subgroups generally showed significantly higher values in both shades $(P=0.036, P<.001)$ (Table 2). Beyond was generally more efficient, followed by LumaWhitePlus. The least whitening values were obtained with Opalescence Boost subgroups (Table 3).

Surface roughness results are shown in Tables 4 and 5 . Figures 1 through 4 show images of sur- 
face roughness histograms in 3D for some representative specimens. With regard to the effect of composite brand on surface roughness (Table 4), TPH3 subgroups showed significantly higher values compared to $D F$ in shade $A 2$, after first $(P=0.011)$ and second bleaching sessions $(P<.001)$. However, the reverse was encountered in shade A4. As for the effect of the bleaching agent (Table 5), LumaWhite-Plus subgroups showed significantly higher values in shade $A 2$, after the second bleaching session $(P<.001)$. With shade $A 4$, Opalescence Boost resulted in significantly higher surface roughness compared to the other subgroups after the first bleaching session $(P=0.039)$. After the second bleaching session, both Opalescence Boost and LumaWhite-Plus subgroups showed significantly higher surface roughness values compared to Beyond subgroup $(P<.001)$.

Pearson's correlation coefficient indicated that a positive correlation existed between color and surface roughness changes for both shades of composites tested. However, this correlation was only statistically significant after the second bleaching session.

\section{DISCUSSION}

Color evaluation was performed using a colorimeter, which expresses color coordinates ac-

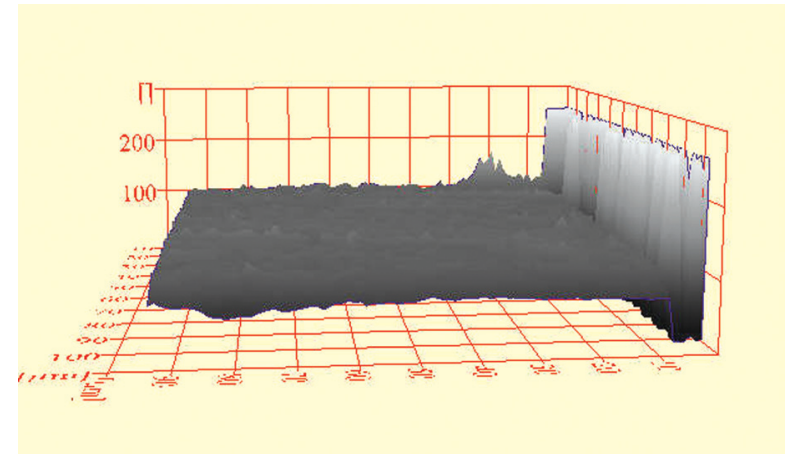

Figure 1. ESEM histogram of a DF control specimen in shade A4.

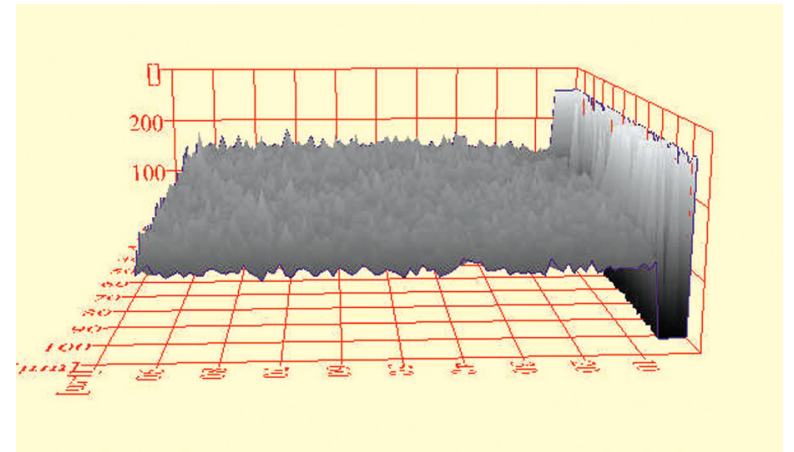

Figure 3. ESEM histogram of a TPH3 control specimen in shade A4.

\section{April 2010 - Vol.4}

cording to the CIELab color system. Other methods of color determination have been used in dentistry, including visual assessment and spectrophotometry, with the instrumental methods generally being considered more precise, as they eliminate subjective errors. ${ }^{19}$ More importantly, the CIELab color system is widely popular and was developed for characterization of colors based on human perception. In this system color difference value, $\Delta \mathrm{E}$, is expressed as a relative color change between successive color measurements. It is generally agreed that a value of $\Delta \mathrm{E} \geq 3.3$ is considered clinically perceptible..$^{20-22}$

The bleaching procedures adopted in the current study simulated in-office bleaching application using different bleaching systems. A high intensity halogen blue light was used to activate the peroxide in one system, while the second system used light emitting diode (LED) technology. To assess the effect of light activation on the bleaching results, the third system tested (Opalescence Boost) required no light activation and depended solely on chemical activation.

The results of the present study are in agreement with the findings of a recently published study. ${ }^{23}$ More specifically, they revealed that none of the bleaching systems notably changed the color of any of the composites tested after the initial

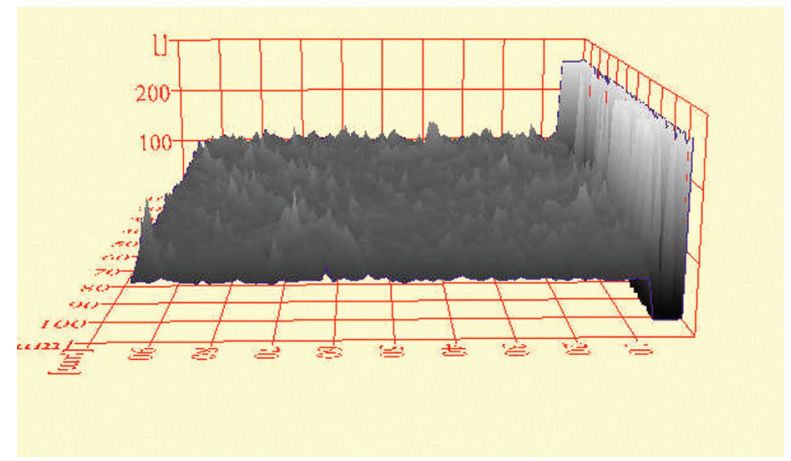

Figure 2. ESEM histogram of a DF specimen in shade A4 after initial bleaching with LumaWhite-Plus.

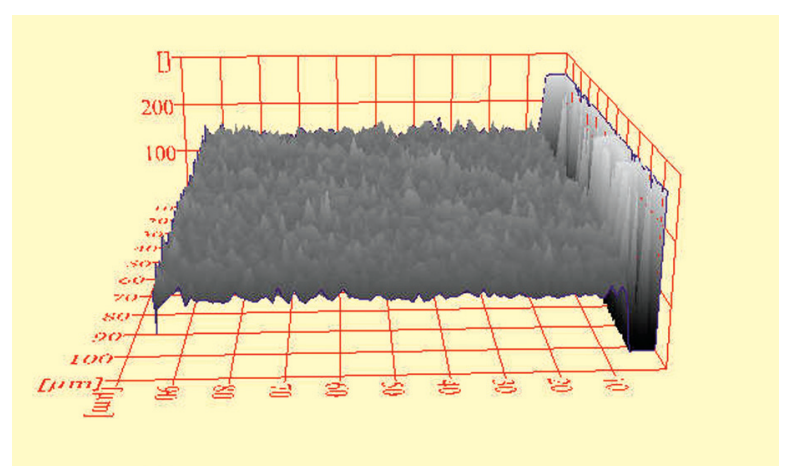

Figure 4. ESEM histogram of a TPH3 specimen in shade A4 after initial bleaching with LumaWhite-Plus. 
bleaching session $(\Delta E<2)$. Also, no significant difference was found between the two composites. This confirms that freshly prepared composites are color-stable. Similar results were found by Hubbezoglu et al, who reported that color change in both microfill and microhybrid resins after bleaching with $35 \%$ hydrogen peroxide for a total of 30 minutes did not exceed $3.3 .^{15}$ In contrast, Monaghan et al found that in-office bleaching significantly affected the color of different composites; they reported $\Delta \mathrm{E}$ values greater than $3 .{ }^{14}$ However, their bleaching protocol consisted of a pre-etching procedure using phosphoric acid, followed by four cycles (30 minutes each) of bleaching using 30\% hydrogen peroxide along with infrared light activation. The procedure they used is much more aggressive than those followed in the current study, which may explain the discrepancy between the findings. Much greater $\Delta \mathrm{E}$ values $(>6)$ were reported by other studies that used in-office bleaching on teeth. ${ }^{24,25}$ Comparing the current results to those obtained in these studies, it is concluded that composites do not bleach to the same degree as teeth. Therefore, replacement of such restorations may be a more effective option.

While $\Delta \mathrm{E}$ values obtained after the first bleaching session were low, the Beyond system resulted in significantly higher bleaching values compared to the other two bleaching agents with shades A2. This may be attributed to the high intensity halogen light activation used with this bleaching agent, which may have resulted in increased whitening. Janda et al demonstrated that composite color stability depends on the type of light used during the curing process, and that the use of tungsten halogen light results in bleaching of composite color by greater conversion of the camphorquinone initiators. ${ }^{6}$ Whether the increased whitening achieved with Beyond was due to enhancement of the oxidative process of the bleaching gel or to added conversion of remaining initiators requires further investigation.

The second treatment to which the composites were subjected was a staining procedure which reflects the conditions in the oral environment, in which restorations are exposed to coffee drinks. Coffee was chosen in this study as a staining solution because it has been shown to have a strong staining effect on composites as well as on natural teeth. ${ }^{26,27}$ According to Um and Ruyter, ${ }^{28}$ discoloration by coffee occurs by both adsorption and absorption of colorants by resin-based restorative materials. The authors explained that this was probably due to the compatibility of the polymer phase of the resinous materials with the yellow colorant of coffee, which served to facilitate this adsorption and penetration of colorants. According to the coffee manufacturer, the average time needed to consume a cup of coffee is 15 minutes; coffee drinkers ingest an average of 3.2 cups of coffee per day. Therefore, 48 hours of storage in a coffee solution simulated an average of two months of coffee consumption.

In the present study, DF showed more staining than TPH3, particularly in shade A4. The explanation for this finding lies in the composition of the

Table 1. Details about bleaching agents used: manufacturer, concentration, $\mathrm{pH}$, number of applications and total tooth contact time.

\begin{tabular}{|c|c|c|c|c|c|c|}
\hline Bleaching system & $\begin{array}{l}\text { Activating } \\
\text { light source }\end{array}$ & $\begin{array}{l}\text { Bleaching material } \\
\text { dispensing }\end{array}$ & $\mathrm{H}_{2} \mathrm{O}_{2} \%$ & $\mathrm{pH}$ & $\begin{array}{c}\text { Number of } \\
\text { application } x \text { time/cycle }\end{array}$ & $\begin{array}{l}\text { Total material } \\
\text { contact time }\end{array}$ \\
\hline $\begin{array}{l}\text { Beyond } \\
\text { Beyond Technology Corp. } \\
\text { Santa Clara, California, USA }\end{array}$ & $\begin{array}{c}\text { Beyond } \\
\text { Whitening } \\
\text { Accelerator } \\
\text { High-Intensity Light } \\
\text { WL: } 480-520 \mathrm{~nm}\end{array}$ & Gel supplied in syringe & $35 \%$ & $4.0-5.5$ & $3 \times 8$ minutes/ cycle & $\begin{array}{c}24 \\
\text { minutes }\end{array}$ \\
\hline $\begin{array}{l}\text { LumaWhite Plus } \\
\text { LumaLite, Inc., } 2810 \text { Via Orange } \\
\text { Way, Spring Valley, CA, USA }\end{array}$ & $\begin{array}{l}\text { LumaCool LED Light } \\
\text { WL: } 380-530 \mathrm{~nm}\end{array}$ & $\begin{array}{c}\text { Powder and Liquid } \\
\text { Mixed and applied with brush }\end{array}$ & $35 \%$ & 5.6 & $3 \times 8$ minutes $/$ cycle & $\begin{array}{c}24 \\
\text { minutes }\end{array}$ \\
\hline $\begin{array}{l}\text { Opalescence Boost } \\
\text { Ultradent Products, Inc., } \\
\text { South Jordan, Utah, USA. }\end{array}$ & none & $\begin{array}{l}\text { Gel supplied in } 2 \text { separate } \\
\text { syringes } \\
\text { Mixed and applied with } \\
\text { mixing tip }\end{array}$ & $38 \%$ & 7 & $3 \times 15$ minutes/cycle & $\begin{array}{c}45 \\
\text { minutes }\end{array}$ \\
\hline
\end{tabular}


materials. The resin matrix composition and the amount of filler loading are different among the two composites. Bis-GMA and TEGDMA are both hydrophilic monomers, but water uptake in BisGMA resins ranges from 3 to $6 \%$, while in TEGDMA it ranges from 0 to $1 \% .{ }^{8}$ According to the information provided by the manufacturers, TPH3 resin matrix is based on Bis-GMA-adduct and TEGDMA, while DF is based on Bis-GMA only, rendering the latter more subject to water uptake, with subsequent discoloration. In addition, $\mathrm{TPH} 3$ is a microhybrid resin composite with $58 \%$ by volume filler loading, compared to $40 \%$ by volume for microfilled DF. Therefore, the higher staining of DF might have been influenced by the relatively higher volume of the resin matrix.

In both shades tested, whitening of the stained specimens was greater with Beyond and LumaWhite-Plus. This may suggest that light-activated bleaching had a greater whitening effect on

Table 2. Means and standard deviation values for color change $(\Delta E)$ for all subgroups of the two composites in shade A2.

\begin{tabular}{|c|c|c|c|c|c|c|}
\hline Variable & Material & $\begin{array}{l}\text { Bleaching } \\
\text { agents }\end{array}$ & Mean $\Delta \mathrm{E}$ & SD & $\begin{array}{c}\text { Regression } \\
\text { analysis for } \\
\text { materials }\end{array}$ & $\begin{array}{l}\text { Regression } \\
\text { analysis for } \\
\text { bleach agents }\end{array}$ \\
\hline \multirow{6}{*}{ After first bleach } & \multirow{3}{*}{ Durafil VS } & Beyond & 1.97 & 0.45 & \multirow{6}{*}{0.976} & \multirow{6}{*}{$0.009 *$} \\
\hline & & Luma & 1.07 & 0.47 & & \\
\hline & & Opal XB & 0.56 & 0.014 & & \\
\hline & \multirow{3}{*}{ TPH3 } & Beyond & 1.28 & 0.056 & & \\
\hline & & Luma & 0.84 & 0.12 & & \\
\hline & & Opal XB & 1.47 & 0.3 & & \\
\hline \multirow{6}{*}{ After staining } & \multirow{4}{*}{ Durafil VS } & Beyond & $2.95(-)$ & 0.29 & \multirow{6}{*}{0.15} & \multirow{6}{*}{$0.025^{*}$} \\
\hline & & Luma & $3.40(-)$ & 0.24 & & \\
\hline & & Opal XB & $2.02(-)$ & 0.73 & & \\
\hline & & Beyond & $2.04(-)$ & 0.36 & & \\
\hline & \multirow[t]{2}{*}{ TPH3 } & Luma & $2.82(-)$ & 0.18 & & \\
\hline & & Opal XB & $2.54(-)$ & 0.13 & & \\
\hline \multirow{6}{*}{ After second bleach } & \multirow{4}{*}{ Durafil VS } & Beyond & 2.02 & 0.58 & \multirow{6}{*}{0.302} & \multirow{6}{*}{0.986} \\
\hline & & Luma & 1.78 & 0.03 & & \\
\hline & & Opal XB & 1.38 & 0.79 & & \\
\hline & & Beyond & 1.14 & 0.65 & & \\
\hline & \multirow[t]{2}{*}{ TPH3 } & Luma & 1.43 & 0.27 & & \\
\hline & & Opal XB & 1.72 & 0.02 & & \\
\hline \multirow{6}{*}{$\begin{array}{l}\text { Between staining and } \\
\text { second bleach }\end{array}$} & & Beyond & 3.11 & 0.98 & \multirow{6}{*}{$0.036^{*}$} & \multirow{6}{*}{$0.007^{*}$} \\
\hline & Durafil VS & Luma & 2.73 & 0.47 & & \\
\hline & & Opal XB & 0.93 & 0.24 & & \\
\hline & \multirow{3}{*}{ TPH3 } & Beyond & 1.64 & 0.23 & & \\
\hline & & Luma & 1.8 & 0.26 & & \\
\hline & & Opal XB & 1.42 & 0.05 & & \\
\hline
\end{tabular}

*: Significant at $P \leq .05$ 
stained composite. Generally, the mechanism of color change in resin composite when exposed to vital bleaching regimes includes oxidation of surface pigments, oxidation of amine compounds (which are responsible for color stability over time), or breakdown of poorly polymerized resin matrix. ${ }^{14}$ These effects could have been enhanced by the use of light-activation during the bleaching. However, the benefit of using light-activated bleaching on tooth structure has been widely debated. ${ }^{29-31}$ Therefore, it may be concluded that the use of light might be more beneficial in bleaching restorative resins than tooth structure.

It has been generally accepted that a rough restoration surface is more susceptible to staining in the oral environment because it provides increased surface area compared to a smooth surface. ${ }^{32}$ Several methods have been employed to characterize surface roughness. These included contact stylus tracing profilometry, non-contact profilometry, atomic force microscopy, and scanning electron microscopy. ${ }^{32,33}$ In the present study, ESEM was combined with image analysis to provide both qualitative and quantitative assessments of surface roughness. This technique is considered the most significant and most frequently used.

Composite resins have been controversial. Wattanapayungkul et al found that bleaching with $35 \%$ hydrogen peroxide was not detrimental to the surface finish of composites, ${ }^{17}$ while Moraes et al found that bleaching using $35 \%$ hydrogen or carbamide peroxide resulted in significantly higher surface roughness in microhybrid, but not in microfilled, composite resins. ${ }^{35}$ Silva et al found in

Table 3. Means and standard deviation values for color change $(\Delta E)$ for all subgroups of the two composites in shade A4.

\begin{tabular}{|c|c|c|c|c|c|c|}
\hline Variable & Material & $\begin{array}{l}\text { Bleaching } \\
\text { agents }\end{array}$ & Mean $\Delta \mathrm{E}$ & SD & $\begin{array}{c}\text { Regression } \\
\text { analysis for } \\
\text { materials }\end{array}$ & $\begin{array}{l}\text { Regression } \\
\text { analysis for } \\
\text { bleach agents }\end{array}$ \\
\hline \multirow{6}{*}{ After first bleach } & & Beyond & 0.66 & 0.22 & \multirow{6}{*}{0.496} & \multirow{6}{*}{0.519} \\
\hline & Durafil VS & Luma & 0.82 & 0.17 & & \\
\hline & \multirow{4}{*}{ TPH3 } & Opal XB & 0.73 & 0.14 & & \\
\hline & & Beyond & 0.6 & 0.16 & & \\
\hline & & Luma & 0.54 & 0.26 & & \\
\hline & & Opal XB & 0.84 & 0.36 & & \\
\hline \multirow{6}{*}{ After staining } & \multirow{3}{*}{ Durafil VS } & Beyond & $(-) 4.44$ & 1.52 & \multirow{6}{*}{$0.001 *$} & \multirow{6}{*}{0.587} \\
\hline & & Luma & $(-) 3.43$ & 0.55 & & \\
\hline & & Opal XB & $(-) 4.06$ & 1.49 & & \\
\hline & \multirow{3}{*}{ TPH3 } & Beyond & $(-) 2.12$ & 0.33 & & \\
\hline & & Luma & $(-) 2.02$ & 0.34 & & \\
\hline & & Opal XB & $(-) 1.68$ & 0.49 & & \\
\hline \multirow{6}{*}{ After second bleach } & & Beyond & 0.91 & 0.21 & \multirow{6}{*}{$0.035^{*}$} & \multirow{6}{*}{0.114} \\
\hline & Durafil VS & Luma & 1.55 & 0.52 & & \\
\hline & & Opal XB & 3.71 & 1.8 & & \\
\hline & \multirow{3}{*}{ TPH3 } & Beyond & 1.31 & 0.49 & & \\
\hline & & Luma & 1.49 & 0.35 & & \\
\hline & & Opal XB & 0.64 & 0.26 & & \\
\hline $\begin{array}{l}\text { Between staining and } \\
\text { second bleach }\end{array}$ & & Beyond & 4.16 & 1.09 & $<0.001^{*}$ & $0.002^{*}$ \\
\hline
\end{tabular}


an in situ study that bleaching using 35\% hydrogen peroxide paint-on whitener had no significant effect on surface roughness of posterior composite or on microfilled composite. ${ }^{13}$ In this study, surface roughness was measured at baseline then after the first and second bleaching sessions; the results correlated well to the color changes obtained. It was interesting to observe that the different shades of composites behaved differently in terms of surface roughness in response to the different bleaching treatments. In the A2 shade, TPH3 showed significantly higher surface roughness than DF, which is explainable when one knowing that DF is a microfilled composite with smaller filler particle size compared to TPH3, which is a microhybrid composite with variable size fillers. In contrast, with A4 shade, the reverse was encountered. DF had significantly higher surface roughness, an observation that could not be explained within the scope of this study but indicates that different shades of the same composite might behave differently under the same conditions.

The resin matrix of composites might become chemically degraded by the concentration or repeated application of peroxide. In addition, if the bleaching agent degraded the coupling agent of resin composites, the resultant roughness would

Table 4. Means and standard deviation values for surface roughness for all subgroups of the two composites in shade A2.

\begin{tabular}{|c|c|c|c|c|c|c|}
\hline Variable & Material & Bleach & Mean & SD & $\begin{array}{c}\text { Regression } \\
\text { analysis for } \\
\text { materials }\end{array}$ & $\begin{array}{l}\text { Regression analysis } \\
\text { for bleach agents }\end{array}$ \\
\hline \multirow{8}{*}{ After first bleach } & \multirow{4}{*}{ Durafil VS } & Control & 126.1 & 5.3 & \multirow{8}{*}{$0.011^{*}$} & \multirow{8}{*}{0.39} \\
\hline & & Beyond & 137.6 & 13.2 & & \\
\hline & & Luma & 131 & 13.1 & & \\
\hline & & Opal & 127.5 & 6.5 & & \\
\hline & \multirow{4}{*}{ TPH3 } & Control & 150.1 & 9.7 & & \\
\hline & & Beyond & 125.6 & 6.5 & & \\
\hline & & Luma & 143.3 & 6.6 & & \\
\hline & & Opal & 138 & 5.7 & & \\
\hline After second bleach & Durafil VS & Control & 126.1 & 5.3 & $<0.001 *$ & $<0.001 *$ \\
\hline
\end{tabular}

*: Significant at $\mathrm{P} \leq .05$

Table 5. Means and standard deviation values for surface roughness for all subgroups of the two composites in shade A4.

\begin{tabular}{|c|c|c|c|c|c|c|}
\hline Variable & Material & Bleach & Mean & SD & $\begin{array}{c}\text { Regression } \\
\text { analysis for } \\
\text { materials }\end{array}$ & $\begin{array}{l}\text { Regression analysis } \\
\text { for bleach agents }\end{array}$ \\
\hline \multirow{8}{*}{ After first bleach } & \multirow{4}{*}{ Durafil VS } & Control & 106.7 & 2.1 & \multirow{8}{*}{$<0.001 *$} & \multirow{8}{*}{$0.039 *$} \\
\hline & & Beyond & 107.2 & 2.4 & & \\
\hline & & Luma & 109.2 & 2.1 & & \\
\hline & & Opal & 114.3 & 2 & & \\
\hline & \multirow{4}{*}{ TPH3 } & Control & 100.5 & 5.3 & & \\
\hline & & Beyond & 102.6 & 8.1 & & \\
\hline & & Luma & 100.2 & 4.9 & & \\
\hline & & Opal & 106.1 & 5.9 & & \\
\hline After second bleach & Durafil VS & Control & 106.7 & 2.1 & $<0.001^{*}$ & $<0.001 *$ \\
\hline
\end{tabular}

*: Significant at $\mathrm{P} \leq .05$ 
be exaggerated. ${ }^{36}$ In the current study, it was observed that the type of bleaching system had a significant effect on roughness. The bleaching agents used differed in $\mathrm{pH}$ and duration of application. The low $\mathrm{pH}$ of the LumaWhite-Plus bleaching system could have been the reason why significantly higher surface roughness was obtained after the second bleaching session with shade A2. It appears that the effect of $\mathrm{pH}$ was, on the other hand, surpassed by the effect of the duration of application of the bleaching agent. When Opalescence Boost bleaching, which has a neutral $\mathrm{pH}$ but a longer gel contact time (45 minutes), was applied, it resulted in significantly higher surface roughness compared to the other bleaching agents $(24$ minutes of gel contact timel after initial bleaching in the A4 shade. However, after re-bleaching, no significant difference was found between Opalescence Boost and LumaWhite. Both had higher values than Beyond and the control groups. Nevertheless, it was surprising to find that Beyond, having an acidic $\mathrm{pH}$ and the same contact time as the LumaWhite-Plus, resulted in significantly lower surface roughness, even when compared to the controls, particularly after re-bleaching. It has been postulated that peroxides might induce oxidative cleavage of polymer chains and, therefore, any un-reacted double bonds are expected to be the most vulnerable parts of the polymer. ${ }^{37}$ In case of Beyond, the high intensity light used during bleaching might have resulted in greater double bond formation in the resin matrix, rendering it less vulnerable to the detrimental effects of the peroxide.

Whether greater bleaching results would automatically reflect on increased roughness, the results of the current study indicate that it is material-dependent. Beyond bleaching, which showed superior results after initial bleaching, did not result in a rough surface; in fact, a significantly smoother surface was observed. On the other hand, LumaWhite-Plus resulted in significantly higher surface roughness with both shades, indicating that despite its ability to remove stains, it might render the composite surface rougher and more susceptible to future discoloration. The significantly positive correlation between color and surface roughness after the second bleaching corroborates the fact that successful bleaching of discolored restorations might increase surface roughness of resin composites.

\section{CONCLUSIONS}

- Durafil VS was more affected by bleaching and more subject to staining than TPH3.

- In-office bleaching may remove surface stains from composite restorations, but it will not whiten unstained ones.

- The two light-activated bleaching systems were more effective in removing surface stains from composite than was a chemically activated one.

- Increased surface roughness of composites as a result of bleaching appears to be dependent on the bleaching agent used as well as the composite material type and shade.

\section{ACKNOWLEDGMENTS}

This work was supported in part with a grant from the Egyptian Ministry of Research and Higher Education. Sample materials were provided by Dentsply, Kulzer, Beyond, Lumalite and Ultradent to whom the authors are grateful.

\section{REFERENCES}

1. Kugel G, Kastali S. Tooth whitening efficacy and safety: a randomized and controlled clinical trial. Compend Contin Educ Dent 2000;29:516-521.

2. Dahl JE. Tooth bleaching - a critical review of the biological aspects. Critic Rev Oral Bio Med 2003;14:292-304.

3. Haywood VB, Heymann HO. Nightguard vital bleaching. Quint Int 1989;20:173-176.

4. Greenwall L. Bleaching techniques in restorative dentistry; an illustrated guide. 2001 Martin Duntz Ltd, United Kingdom.

5. Schulze KA, Marshall SJ, Gansky SA, Marshall GW. Color stability and hardness in dental composites after accelerated aging. Dent Mater 2003;19:612-619.

6. Janda R, Roulet JF, Kaminsky M, Steffin G, Latta M. Color stability of resin matrix restorative materials as a function of methods of light activation. Eur J Oral Sci 2004;112:280285

7. Ertas E, Güler AU, Yücel AC, Güler E. Color stability of resin composite after immersion in different drinks. Dent Mater J $2006 ; 25: 371-376$

8. Bagheri R, Burrow MF, Tyas M. Influence of food simulating solutions and surface finish on susceptibility to staining of esthetic restorative materials. J Dent 2005;33:389-398.

9. Fujita M, Kawakimi S, Noda M, Sano H. Color changes of newly developed esthetic restorative material immersed in food simulating liquid. Dent Mater J 2006;25:352-359. 
10. Yalcin F, Gurgan S. Effect of two bleaching regimens on the gloss of tooth colored restorative materials. Dent Mater 2005;21:464-468.

11. Lu H, Roeder LB, Lei L, Powers JM. Effect of surface roughness on stain resistance of dental composites. $J$ Esthet Restor Dent 2005;17:102-108.

12. Polydoron 0, Hellwig E, Auschill TM. The effect of different bleaching agents on the surface texture of restorative materials. Oper Dent 2006;31:473-480.

13. Silva MF, Davies RM, Stewart B, De Vizio W, Tonholo J, Da Silva Junior JG, Pretty IA. Effect of whitening gels on the surface roughness of restorative materials in situ. Dent Mater 2006;22:919-924.

14. Monaghan P, Trowbridge T, Lautenschlager E. Composite resin color change after vital tooth bleaching. $J$ Prosthet Dent 1992;67:778-781.

15. Hubbezoglu I, Akaoglu B, Dogan A, Deskin S, Bolayir G. Effect of bleaching on color change and refractive index of dental composite resins. Dent Mater J 2007;27:105-116.

16. Bowles WH, Lancaster LS, Wagner MJ. Reflectance and texture changes in bleached composite resin surfaces. $J$ Esthet Dent 1996;8:229-233.

17. Wattanapayungkul P, Yap AU. Effects of in-office bleaching products on surface finish of tooth-colored restorations. Oper Dent 2003;28:15-19.

18. Central Bureau of the International Commission on Illumination. Colorimetry CIE publication 1986, Vienna, Austria.

19. Joiner A. Tooth color: review of literature. J Dent 2004;32:312.

20. Johnston WM, Kao EC. Assessment of appearance match by visual observation and clinical colorimetry. $J$ Dent Res 1989;68:819-822.

21. Ruyter IE, Nimler K, Moller B. Color stability of dental composite resin materials for crown and bridge veneers. Dent Mater 1987;3:246-251.

22. Seghi RR, Helwett ER, Kim J. Visual and instrumental colorimetric assessments of small color differences on translucent dental porcelain. J Dent Res 1989;68:1760-1764.

23. Yu H, Pan X, Lin Y, Li Q, Hussain M, Wang Y. Effects of carbamide peroxide on the staining susceptibility of tooth-colored restorative materials. Oper Dent 2009;43:72-82.

24. Sulieman M, Addy M, MacDonald E, Rees JS. The effect of hydrogen peroxide concentration on the outcome of tooth whitening: an in-vitro study. J Dent 2004;32:295-299.

25. Matis BA, Cochran MA, Ranco M, Al-Ammar W, Eckert GJ, Stropes M. Eight in-office tooth whitening systems evaluated in vivo: a pilot study. Oper Dent 2007;32:322-327.

26. Multu-Saḡesen L, Ergün G, Özkan Y, Semiz M. Color stability of dental composite after immersion in various media. Dent Mater J 2005;24:382-390.
27. Abu-Bakr N, Han L, Okamoto A, Iwaka M. Color stability of compomer after immersion in various media. $J$ Esthet Dent 2000;12:258-263.

28. Um CM, Ruyter IE. Staining of resin-based veneering materials with coffee and tea. Quint Int 1991;22:377-386.

29. Kugel G, Papathanasiou A, Williams AJ 3rd, Anderson C, Ferreira S. Clinical evaluation of chemical and light-activated tooth whitening systems. Compend Contin Educ Dent 2006;27:54-62.

30. Sulieman M, MacDonald E, Rees JS, Addy M. Comparison of three in-office bleaching systems based on 35\% hydrogen peroxide with different light activators. Am J Dent 2005;18:194-197.

31. Marson FC, Sensi LG, Vieira LCC, Araijo E. Clinical evaluation of in-office dental bleaching treatments with and without the use of light-activation sources. Oper Dent 2008;33:15-22.

32. Tholt B, Miranda-Junior WG, Prioli R, Thompson J, Oda $M$. Surface roughness in ceramics with different finishing techniques using atomic force microscope and profilometer. Oper Dent 2006;31:442-449.

33. Whitehead SA, Shearer AC, Watts DC, Wilson NHF. Comparison of two stylus methods for measuring surface texture. Dent Mater 1999;15:79-86.

34. Joniot S, Soloman JP, Dejou J, Grégoire G. Use of two surface analyzers to evaluate the surface roughness of four esthetic restorative materials after polishing. Oper Dent 2006;31:39-46.

35. Moraes RR, Marimon LM, Schneider LFJ, Correr L, Camacho GB, Bueno M. Carbamide peroxide bleaching agents: effects on surface roughness of enamel, composite and porcelain. Clin Oral Investig 2006:10:23-28.

36. Kim JH, Lee YK, Lim BS, Rhee SH, Yang HC. Effect of tooth whitening strips and films on changes in color and surface roughness of resin composites. Clin Oral Investig 2004;8:118-122.

37. Hannig C, Duong S, Becker K, Brunner E, Kahler E, Attin T. Effect of bleaching on subsurface microhardness of composite and a polyacid modified composite. Dent Mater 2007;23:198-203. 